\title{
A Restriction Enzyme Cleavage Map of the Histidine Utilization (hut) Genes of Klebsiella aerogenes and Deletions Lacking Regions of hut DNA
}

\author{
S.A. Boylan ${ }^{1}$, Linda J. Eades $^{1}$, Kaaren A. Janssen ${ }^{2}$, Margaret I. Lomax ${ }^{1}$, and R.A. Bender ${ }^{1}$ \\ ${ }^{1}$ Department of Cellular and Molecular Biology, Division of Biological Sciences, University of Michigan, \\ Ann Arbor, MI 48109, USA \\ ${ }^{2}$ Department of Chemistry, University of California, San Diego, La Jolla, CA 92093, USA
}

\begin{abstract}
Summary. The histidine utilization (hut) operons of Klebsiella aerogenes were cloned into pBR322. The hut genes are wholly contained on a 7.9 kilobase pair fragment bounded by HindIII restriction sites and expression of hut is independent of the orientation of the fragment with respect to $\mathrm{pBR} 322$. A restriction map locating the 27 cleavage sites within hut for the enzymes, HindIII, PvuII, SalI, BgIII, $K p n \mathrm{I}$, PstI, SmaI, AvaI, and BamHI was deduced. Several of the cleavage sites for the enzymes HaeIII and Hinft were also mapped. A set of deletion plasmids was isolated by removing various restriction fragments from the original plasmid. These deletions were characterized and were used to assist in mapping restriction sites. This physical characterization of hut DNA opens the way for genetic and molecular analysis of the regulation of hut gene expression in vitro as well as in vivo.
\end{abstract}

\section{Introduction}

The genes for histidine utilization (hut) in Klebsiella aerogenes are arranged as a cluster of five genes lying between gal and bio on the $K$. aerogenes chromosome in the order gal - hutIGCUH - bio (Goldberg and Magasanik 1975; Boylan and Bender 1983). In the closely-related organism Salmonella typhimurium, the hut gene cluster is arranged as two adjacent operons, hutIGC and hutUH, where hutC encodes a repressor of both operons (Smith 1971).

Expression of hut genes is regulated negatively by the hutC product with urocanic acid (the product of the first enzyme in the pathway) being the physiological inducer (Schlesinger et al. 1965). When the repressor is inactivated, hut expression further requires a positive activator for maximal expression, either the catabolite gene activator protein (CAP) in the presence of cyclic AMP (signalling carbon and energy limitation) or an unknown factor signalling nitrogen limitation (Neidhardt and Magasanik 1957; Prival and Magasanik 1971). In addition, the hut gene products are not formed unless an electron acceptor such as oxygen is provided (Goldberg and Hanau 1980).

While the physiology and genetics of the hut genes of $K$. aerogenes are well characterized, almost nothing is

Offprint requests to: R.A. Bender known about the molecular basis for this regulation. To this end, we have isolated a $K$. aerogenes DNA fragment carrying the hut operons in the plasmid pBR322 and have used restriction endonuclease digestion to characterize this plasmid and derivatives in which deletions have removed specific segments of the $K$. aerogenes DNA. We here present the restriction map of the hut DNA and its deleted variants.

\section{Materials and Methods}

Bacterial Strains and Growth Conditions. Plasmid DNA was isolated from $E$. coli strain SF 8 (Struhl et al. 1976) harboring either the plasmid pBR322 or clone pCB101. The hut plasmid pCB101 was purified by retransformation and plasmid pCB101 and its various deletions were subsequently purified from either $E$. coli strain EG47 (Goldberg et al. 1976) or RH202 (Adams et al. 1979). Plasmid-containing strains were grown in L-broth or on L-agar (Bender et al. 1977 ) with ampicillin at $25-80 \mu \mathrm{g} / \mathrm{ml}$ and where appropriate tetracycline at $20 \mu \mathrm{g} / \mathrm{ml}$. Minimal medium consisted of $\mathrm{W}$ salts (Bender et al. 1977) supplemented with $0.4 \%$ glucose, succinate, or histidine as carbon source, and with $0.2 \%$ ammonium sulfate, glutamate, or histidine as nitrogen source. Where indicated, $0.2 \%$ urocanic acid was added to induce the hut operons. For plasmid DNA isolation, strains were grown on M9 casamino acids medium (Anderson 1946) containing ampicillin at $50 \mu \mathrm{g} / \mathrm{ml}$ to a Klett reading of 100 (green filter), amplified with chloramphenicol $(50 \mu \mathrm{g} / \mathrm{ml})$, and harvested after an additional $15-17 \mathrm{~h}$.

Chemicals and Enzymes. The various restriction endonucleases, $T_{4}$ DNA ligase, $\lambda$ and $\phi$ X174 RFII DNA and bacterial alkaline phosphatase were obtained from Bethesda Research Labs; $E$. coli DNA polymerase large fragment from New England Nuclear; and ${ }^{32}$ P-labeled deoxyribonucleoside triphosphates were purchased from Amersham. Agarose and $\mathrm{CsCl}$ were from Miles Laboratories and Kawecki Berylco Industries, respectively.

Isolation and Manipulation of DNA. Purified phage particles of $\lambda \mathrm{d} h u t$ k.a. (Blumenberg and Magasanik 1979, 1981) were the kind gift of Dr. Miroslav Blumenberg. Phage DNA was prepared from these particles by phenol extraction and ethanol precipitation. Plasmid DNA was isolated from an 
SDS-cleared lysate from late-log phase cells. After treatment of the lysate with RNaseA and extraction with phenol:chloroform (1:1), the DNA was recoverd as an ethanol precipitate. Plasmid DNA purified to this step was used for transformations and crude agarose gel analyses, or it was purified further using a $\mathrm{CsCl}$-ethidium bromide step gradient in a vertical rotor (El-Gewely et al. 1982) and used for mapping.

Cleared lysates were also prepared as boiled-Triton extracts (Holmes and Quigley 1981) for plasmid transformations and quick DNA analyses. Transformation of $E$. coli strains with plasmid DNA was carried out by the $\mathrm{MgCl}_{2}-$ $\mathrm{CaCl}_{2}$ method (Lederberg and Cohen 1974). Competent cells were stored in $15 \%$ glycerol at $-80^{\circ} \mathrm{C}$ (Morrison 1977).

Restriction endonuclease digestions and $\mathrm{T}_{4} \mathrm{DNA}$ ligase reactions were carried out under conditions described by the supplier. During the initial cloning of the hut-containing Hind III fragment from $\lambda \mathrm{d} h u t \mathrm{~K}$.a. into pBR322, the digested pBR322 DNA was treated with bacterial alkaline phosphatase. Ligation reactions proceeded overnight at $20^{\circ} \mathrm{C}$ and ligated DNA was ethanol precipitated before it was used for transformation.

Restriction fragments were purified by sucrose density gradient centrifugation as described by El-Gewely and Helling (1980). The digested DNA was extracted with phen$\mathrm{ol}$ :chloroform (1:1), precipitated with ethanol and dissolved in $1 \mathrm{ml}$ of TES $(30 \mathrm{mM}$ Tris $\mathrm{HCl}, 5 \mathrm{mM} \mathrm{Na}$ EDTA, $50 \mathrm{mM} \mathrm{NaCl}$, pH 8) containing $20 \mu \mathrm{g}$ ethidium bromide per ml. Samples of 180 to $270 \mu \mathrm{g}$ were layered on a $38 \mathrm{ml}$ linear, 5-20\% sucrose gradient and spun at $37,000 \mathrm{rpm}$ for $4 \mathrm{~h}$ at $5^{\circ} \mathrm{C}$ in a Beckman VTi 50 rotor. The desired upper band was removed by suction.

Plasmid DNA which had been digested with Hae III (blunt-end), or Sal I or Bgl II ( $5^{\prime}$ extension) was labeled at the $5^{\prime}$-end with $\alpha^{32} \mathrm{P}$-dNTP using $E$. coli DNA polymerase (Klenow fragment). Reaction mixtures $(20 \mu 1)$ contained $60 \mathrm{mM}$ Tris- $\mathrm{HCl}(\mathrm{pH} 8.0), 7 \mathrm{mM} \mathrm{MgCl}, 5 \mathrm{mM}$ dithiothreitol, $1 \mu \mathrm{g}$ of digested DNA, 1 unit of Klenow enzyme and $10 \mu \mathrm{Ci}$ each of all 4 deoxyribonucleotides (only dGTP for HaeIII digests). Reaction mixtures were incubated for $60-90 \mathrm{~min}$ at $0^{\circ} \mathrm{C}$ and reactions were terminated by heating at $65^{\circ} \mathrm{C}$ for $5 \mathrm{~min}$. The DNA was precipitated with ethanol and redissolved in 10-15 $\mu$ l of TES.

$\mathrm{Gel}$ Electrophoresis. The size of restriction fragments was determined by comparison of the electrophoretic mobility of the fragments in agarose gels $(0.7 \%-1.2 \%$ agarose in TBE buffer $[90 \mathrm{mM}$ Tris, $2.5 \mathrm{mM}$ EDTA, $90 \mathrm{mM}$ borate, pH 8.31) with the mobility of known standards (HaeIII digests of $\phi X 174$ RFII, HindIII digests of $\lambda$ DNA, and HinfT digests of pBR322).

In order to establish distance between closely placed restriction sites, end-labeled DNA was digested by a second enzyme as described in the legend to Fig. 5 and the digests were heated to $95^{\circ} \mathrm{C}$ for $5 \mathrm{~min}$ in $80 \%$ formamide and $0.2 \%$ bromophenol blue. Fragments were then separated by electrophoresis through an acrylamide-7M urea denaturing gel (Gilbert and Maxam 1973) in TBE buffer; such gels allowed greater resolution of small fragments than agarose gels. Gels were exposed to Kodax X-Omat AR film with an intensifying screen at $-70^{\circ} \mathrm{C}$. HaeIII fragments of $\phi X 174$ which had been labeled at the $3^{\prime}$-ends were used as size markers in these gels.
Enzyme Assays. Histidase and urocanase assays are described in the accompanying following paper (Boylan and Bender 1983).

\section{Results}

\section{Isolation and Characterization of pCB101}

A 7.9 kilobase pair $(\mathrm{kb})$ HindIII fragment carrying the entire Klebsiella aerogenes hut gene cluster was cloned from $\lambda \mathrm{d} h u t$ (Blumenberg and Magasanik 1979 1981) into the tet gene of plasmid pBR322, as described in Materials and Methods. Ampicillin-resistant transformants were scored for tetracycline-sensitivity and the $\mathrm{Hut}^{+}$phenotype (ability to utilize histidine as sole carbon and nitrogen source). One such transformant was selected and its plasmid, pCB101, was purified by retransformation into strain EG47. The resulting strain (EB670) served as the source of pCB101 DNA in all experiments except where noted.

Plasmid pCB116, containing the same $7.9 \mathrm{~Kb}$ fragment in the reverse orientation was obtained by digesting $\mathrm{pCB} 101$ DNA with HindIII, religating the fragments and transforming strain RH202 with the ligated DNA. The transformants were selected for $\mathrm{Hut}^{+}$and scored $\mathrm{Tet}^{\mathrm{s}}$. The inversion of the HindIII fragment in pCB116 was confirmed as follows. Enzymes that cleave pBR322 and cloned DNA sequences at least once each should create two "junction fragments" which include the two sites where $K$. aerogenes DNA is joined to pBR322. If the $K$. aerogenes sequences in pCB116 are reversed relative to those in pCB101, then the size of the two "junction fragments" generated from pCB116 should differ from the corresponding "junction fragments" generated from pCB101. HindIII and enzymes that do not cleave pBR322 sequences (e.g. KpnI) should generate no such differences. The results of the digests of pCB101 and pCB116 with several enzymes, given in Table 1 , showed that enzymes that cleave pBR 322 once (AvaI, BamHI, Pst $\mathrm{I}$, and $S a l I$ ) show an altered pair of fragments while enzymes that do not cleave within the pBR322 sequences (KpnI and HindIII) showed no differences. Thus pCB116 contains the same hut-bearing HindIII fragment as pCB101 but in the opposite orientation. Both strain EB896, carrying pCB101, and strain EB893, an isogenic strain carrying pCB116, grew with either histidine or urocanate as sole carbon and nitrogen source. Hence, expression of hut functions does not

Table 1. Comparison of restriction fragments from $\mathrm{pCB} 101$ and pCB116

\begin{tabular}{|c|c|c|}
\hline $\begin{array}{l}\text { Restriction } \\
\text { enzyme }\end{array}$ & $\begin{array}{l}\text { pCB101 } \\
\text { Fragment sizes }(\mathrm{kb})\end{array}$ & $\begin{array}{l}\text { pCB116 } \\
\text { Fragment sizes }(\mathrm{kb})\end{array}$ \\
\hline Aval & $4.5,3.7,1.9,1.6,0.7$ & $6.0,2.1,1.9,1.6,0.7$ \\
\hline$B a m \mathrm{HI}$ & $\overline{6.0}, \overline{4.5}, 1.6,0.3,0.16$ & $10.0,1.6,0.45,0.3,0.16$ \\
\hline HindIII & $8.0, \overline{4.5}$ & $\overline{8.0,4.5}$ \\
\hline$K p n \mathbf{I}$ & $8.0,2.2,1.1,0.9$ & $8.0,2.2,1.1,0.9$ \\
\hline PstI & $6.0,2.6,2.1,0.9,0.6$ & $5.5,3.4,2.1,0.9,0.6$ \\
\hline SalI & $8.0, \overline{2} .6,1.4$ & $5.31,5.3,1.4$ \\
\hline
\end{tabular}

Comparison of restriction fragments from pCB101 and pCB116. Plasmids pCB101 and pCB116 were digested with the restriction enzymes indicated and the sizes of the resulting fragments were determined following agarose gel electrophoresis. Junction fragments (as defined in the text and predicted from the map shown in Figs. 1 and 2) are underlined 
require a particular orientation of the cloned fragment relative to $\mathrm{pBR} 322$ sequences.

When present at the normal chromosomal location in Klebsella, hut gene expression is regulated by the hut-specific repressor (Schlesinger et al. 1965), by carbon limitation, and by nitrogen limitation (Prival and Magasanik 1971). The levels of histidase and urocanase from the hutUH operon of pCB101 were measured in $E$. coli, which lacks hut genes. As seen in Table 2, addition of urocanate to the growth medium results in a three- to four-fold induction of both histidase and urocanase (lines 1 and 2), demonstrating control by repressor. A small but reproducible derepression of histidase and urocanase was seen under conditions of nitrogen limited growth (line 3 vs line 2) whereas no derepression was seen under conditions of carbon limited growth (line 4 vs line 2). Failure to observe derepression in succinate minimal medium was not specific to succinate, as enzyme levels were similar in fructose grown cells (not shown). These regulatory phenomena, failure to observe optimal induction with urocanate and failure to observe derepression under carbon limitation, are considered in the discussion.

Table 2. Regulation of histidase and urocanase production from pCB101 in E. coli

\begin{tabular}{lclcc}
\hline Medium & Inducer & Activation & \multicolumn{2}{l}{ Specific activity (units/mg) } \\
\cline { 4 - 5 } & & & Histidase & Urocanase \\
\hline GN & & none & 17 & 1.3 \\
GNgln U & + & none & 50 & 5 \\
GglnU & + & nitrogen & 118 & 10 \\
SNglnU & + & carbon & 57 & 5 \\
\hline
\end{tabular}

Strain EB896 was grown and assayed for histidase and urocanase activities as described in Materials and Methods. Minimal medium supplements were $\mathrm{G}, 0.4 \%$ glucose; $\mathrm{N}, 0.2 \%$ ammonium sulfate; gin, $0.2 \%$ L-glutamine (A grade, Calbiochem, freshly prepared and sterilized by filtration immediately before use); U, $0.2 \%$ urocanic acid; $\mathrm{S}, 0.4 \%$ succinic acid

\section{Isolation and characterization of deletion plasmids}

The isolation of deletions removing various regions of the hut DNA from pCB101 assisted both in the physical mapping of pCB101 (see below) and in the alignment of the physical and genetic maps of hut (Boylan and Bender 1983). When pCB101 was digested to completion with a restriction enzyme and religated at dilute DNA concentrations, only the unique fragment carrying the pBR322 replicator was recovered as a plasmid, all other fragments having been deleted by the procedure. Such deletion plasmids were generated using a variety of restriction enzymes (BglII, KpnI, SalI, AvaI, PvuII) and their structures were characterized by restriction enzyme digestion. As expected, plasmids pCB103 (BglII deletion), pCB113 (KpnI deletion), pCB106 (Sall deletion), pCB115 (AvaI deletion), and pCB110 (PvuII deletion) have unique sites for the enzymes used to construct them (Table 3). Plasmid pCB111 is a KpnI deletion plasmid derived from pCB106 (itself a Sall deletion plasmid) and has unique sites for both KpnI and Sall (Table 3). The structure of the deletions was further tested by analyzing the fragments that would be predicted to span the deletion assuming the restriction map in Fig. 1. Table 4 shows the sizes of the fragments which differ between pCB101 and various deletion plasmids. The size of the deletion can be determined by subtraction, and in every case this value matches the sum of the sizes of the fragments deleted. For example, the only difference between a Bam HI digest of pCB101 and pCB103 is the reduction of a $6.0 \mathrm{~kb}$ fragment in the pCB101 digest to a $2.8 \mathrm{~kb}$ fragment in the pCB103 digest, demonstrating that pCB103 is $3.2 \mathrm{~kb}$ smaller than pCB101 and that the deletion lies in the $6.0 \mathrm{~kb}$ BamHI fragment of pCB101. The $3.1 \mathrm{~kb} B g I \mathrm{II}$ fragment is missing from $\mathrm{pCB} 103$, and the map shown in Fig. 1 places this fragment wholly within the $6.0 \mathrm{~kb}$ BamHI fragment of pCB101. The structures of the deletion plasmids are summarized in Fig. 2.

The deletion plasmid pCB102 is more complex and its isolation is depicted in Fig. 3. We attempted to clone the large $(5.6 \mathrm{~kb}) \mathrm{HindIII}$ to $B a m \mathrm{HI}$ fragment (from position 0 to position 5.6) between the HindIII and BamHI sites

Table 3. Restriction enzyme cleavage site frequencies in pCB101 and its derivatives

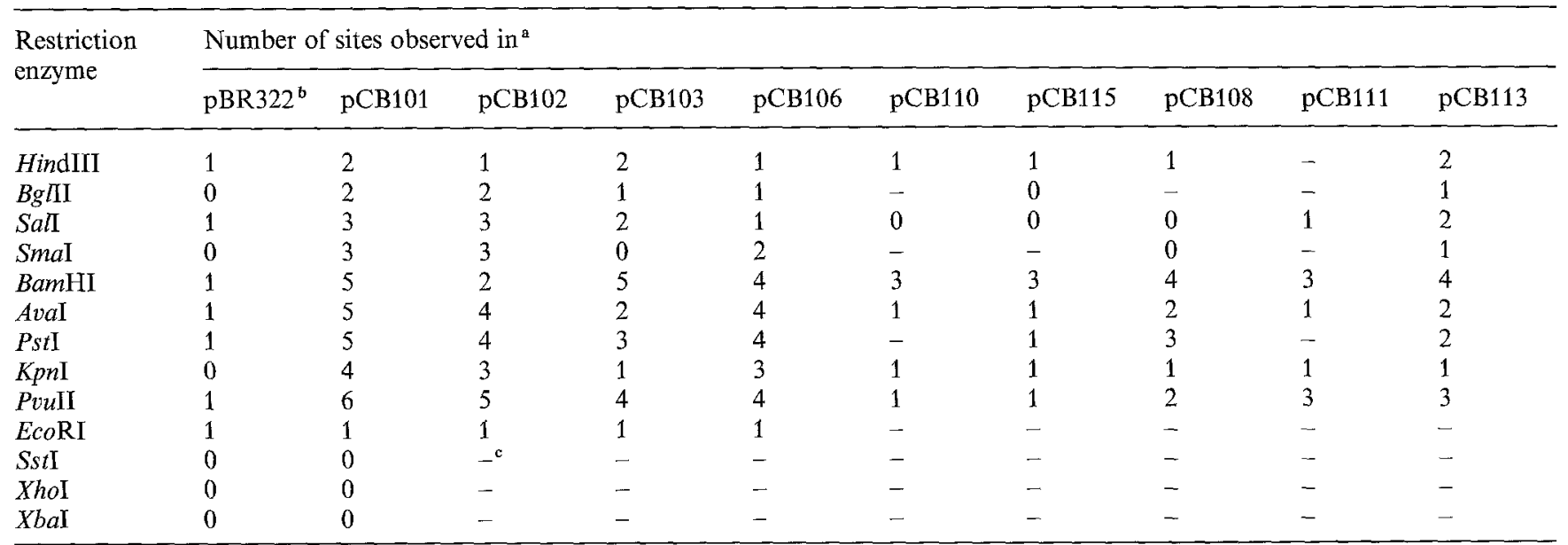

a Number of sites was determined after separating fragments resulting from limit digests on $1 \%$ agarose gels. As a result very close pairs of sites would not have been detected

b Sites for pBR322 are derived from the known nucleotide sequence (Sutcliffe 1978)

c A dash indicates that the number of sites was not determined 


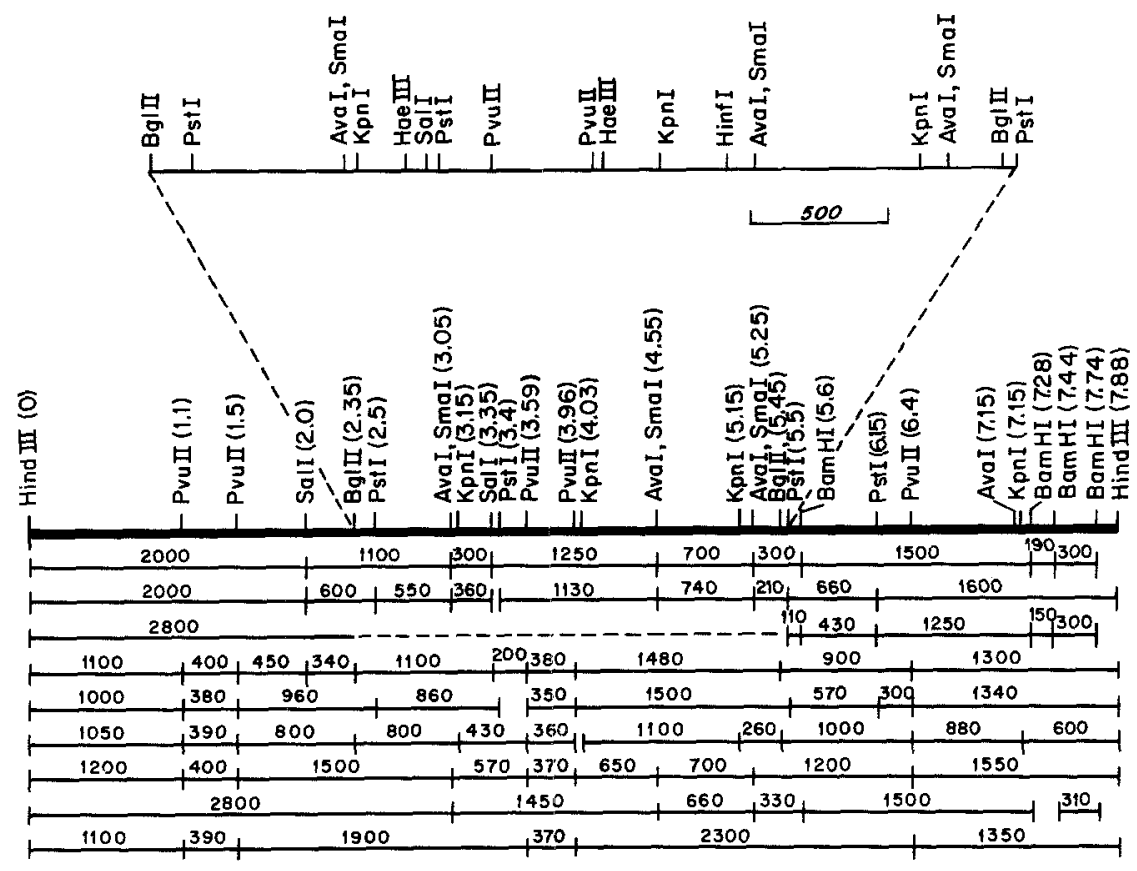

Fig. 1. Restriction map of $K$. aerogenes hut DNA. Distances in base pairs between cleavage sites are indicated by the numbers in the lower portion of the figure. The numbers in parentheses next to the restriction sites indicated on the main line are their map positions (in $\mathrm{kb}$ ) relative to the HindIII site at the left. The upper line represents an expanded map which includes sites for the enzymes HinfI and HaeIII whose complete maps have not yet been determined. The order of the two BamHI fragments between positions 7.28 and 7.74 has not been unambiguously determined, thus the internal BamHI site may lie at either position 7.44 (as indicated) or at position 7.58
Table 4. Sizes of novel junction fragments in deletion plasmids

\begin{tabular}{llll}
\hline Plasmid & Enzyme & Size in pCB101 & $\begin{array}{l}\text { Size in } \\
\text { deleted plasmid }\end{array}$ \\
\hline pCB103 & BamHI & 6.0 & 2.8 \\
pCB102 & Sall & 8.5 & 2.5 \\
pCB106 & PvuII & $2.0,0.4,3.1$ & 1.7 \\
pCB108 & BamHI & 6.0 & 0.47 \\
pCB110 & KpnI & $2.3,1.2,0.88,8.0$ & 3.7 \\
pCB111 & BamHI & $1.7,6.2,4.2$ & 4.7 \\
pCB113 & HindIII & 7.8 & 3.5 \\
pCB115 & BamHI & $1.7,6.2,4.2$ & 3.3 \\
\hline
\end{tabular}

Fragments generated by digestion of a deletion plasmid with a given enzyme were compared with fragments generated by digestion of pCB101 with the same enzyme. Fragments which were non-identical in the two digests are listed in the last two columns. The size of the deletion can be readily calculated by subtracting the size of the fragment in the last column entry from the sum of the fragments in the corresponding entry in the second last column. As in Table 1, fragments were visualized after electrophoresis in $1 \%$ agarose gels, so fragments $<150$ bp are not seen

of $\mathrm{pBR} 322$. In the process, we also cloned a $0.16 \mathrm{~kb}$ BamHIBamHI fragment (positions 7.28 to 7.44 ) at what would otherwise have been the unique BamHI site. In the final structure of $\mathrm{pCB} 102$, the $\mathrm{pBR} 322$ sequences are arranged in an orientation (relative to hut DNA) the reverse of that seen with all the other plasmids except pCB116 (Fig. 2).

\section{Map of Restriction Endonuclease Cleavage Sites in Plasmid pCB101}

These "deletion plasmids" were used to determine the order of restriction sites in pCB101. The BgfII deletion plasmid pCB103 lacks a $3.1 \mathrm{~kb}$ segment from the central region of hut DNA (Blumenberg and Magasanik 1981). Plasmid pCB103 lacks all three of the SmaI sites of pCB101 (Ta- ble 3), establishing the order of sites as BgIII - SmaI SmaI - SmaI - BglII. By comparing the fragments from a Sall digest of pCB103 with the fragments from a Sall - BglII double digest, (Fig. 4), it was deduced that the single SalI site remaining in the hut DNA of pCB103 (Table 3) was closer to the $S a l \mathrm{I}$ site in pBR322 sequences than was the $B g I I I$ site. The other Sall site in pCB101 is missing from the $B g I I I$ deletion plasmid (Table 3). This established the order SalI - BglII - SalI - BglII. This order was confirmed by the observation that the $S a l$ I deletion plasmid pCB106, which removes DNA to the left of the SalI site at position 3.35 (Fig. 1), lacked one of the BglII sites of pCB101 (Table 3). Since pCB106 contains two of the three SmaI sites of pCB101, as well as the BgIII site identified above (Table 3), the order SalI - BglII - SmaI - SalI SmaI - SmaI - BglII was deduced. Once the order of these sites had been established, the distances between sites was determined from an analysis of the sizes of the fragments generated by digestion of pCB101, pCB103, or pCB106 with one or more enzymes (Fig. 1).

Similar arguments were applied using other restriction enzymes and a complete map of restriction enzyme cleavage sites in pCB101 was determined (Fig. 1). The analysis of single and multiple digests of pCB101, pCB103, and pCB106 allowed the ordering of most of the sites shown in Fig. 1, but several pairs of sites were too close to be distinguished by such an analysis. An analysis of the restriction sites remaining in the deletion plasmids permitted an unambiguous ordering of these sites. For example, the order $S m a \mathrm{I}-K p n I$ at position 3.1 was determined since the $K p n \mathrm{I}$ deletion plasmid pCB113, which removes the DNA to the right of this KpnI site, (Fig. 2) leaves the SmaI site intact (Table 3). Similar reasoning confirmed the following orders: KpnI-SalI near map position 3.2, PvuII-KpnI near 4.0, BglII-PstI near 5.5, and AvaI-KpnI near 7.15. This analysis identified the location of all the sites shown on the main line in Fig. 1 except for the second of three BamHI sites in the region from map position 7.3-7.7. This region yields two BamHI fragments of 0.3 and $0.16 \mathrm{~kb}$ whose order 


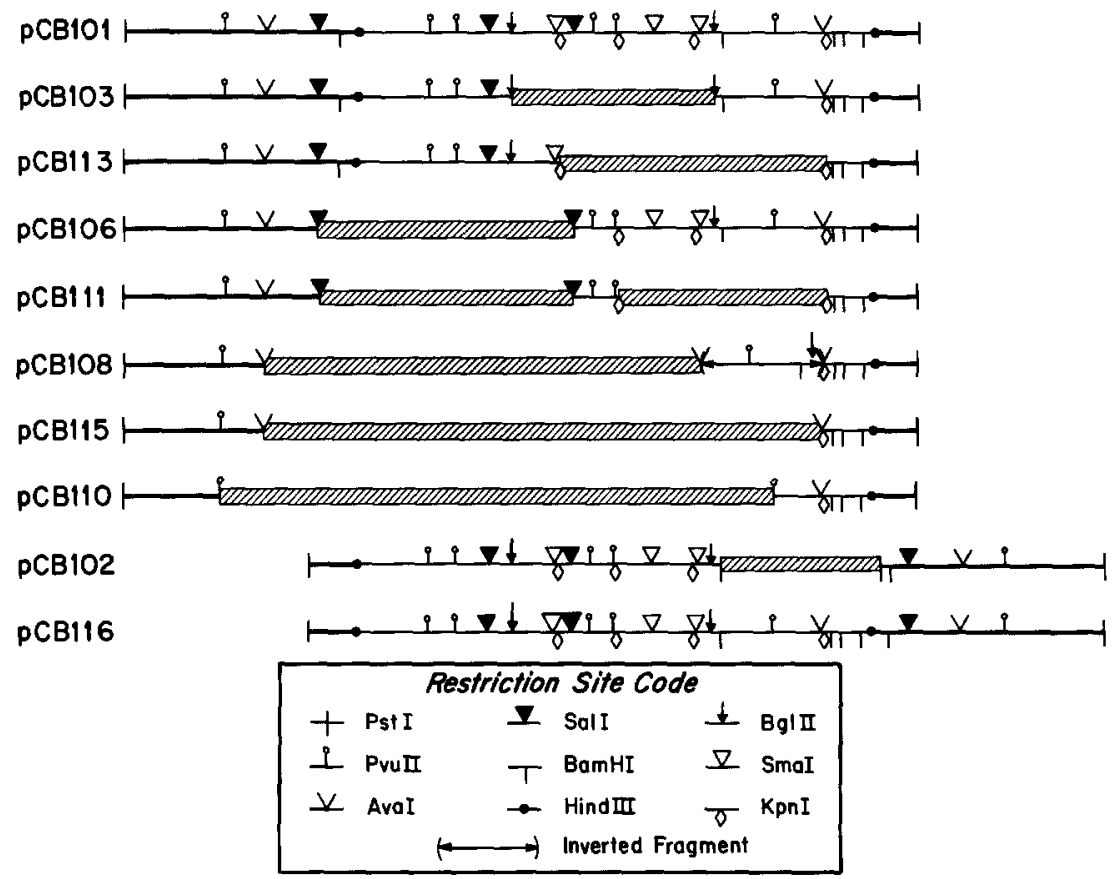

Fig. 2. Map of deletion plasmids derived from pCB101. Each deletion plasmid (generated as described in the text) was digested with the enzymes indicated and the sizes of the resulting fragments were determined following agarose gel electrophoresis. A partial restriction map for each plasmid was determined by comparison with the fragments generated by digestion of pCB101 (see Fig. 1 for complete map). The heavy line represents pBR322 DNA sequences, the light line represents $K$. aerogenes (hut) DNA sequences, and the cross-hatched box area represents deleted DNA. These maps confirm that the endpoints of the deletions are defined by the restriction enzymes used to generate the deletions. Note that for plasmids pCB102 and pCB116 the orientation of the pBR322 sequences relative to the $K$. aerogenes DNA sequences is reversed

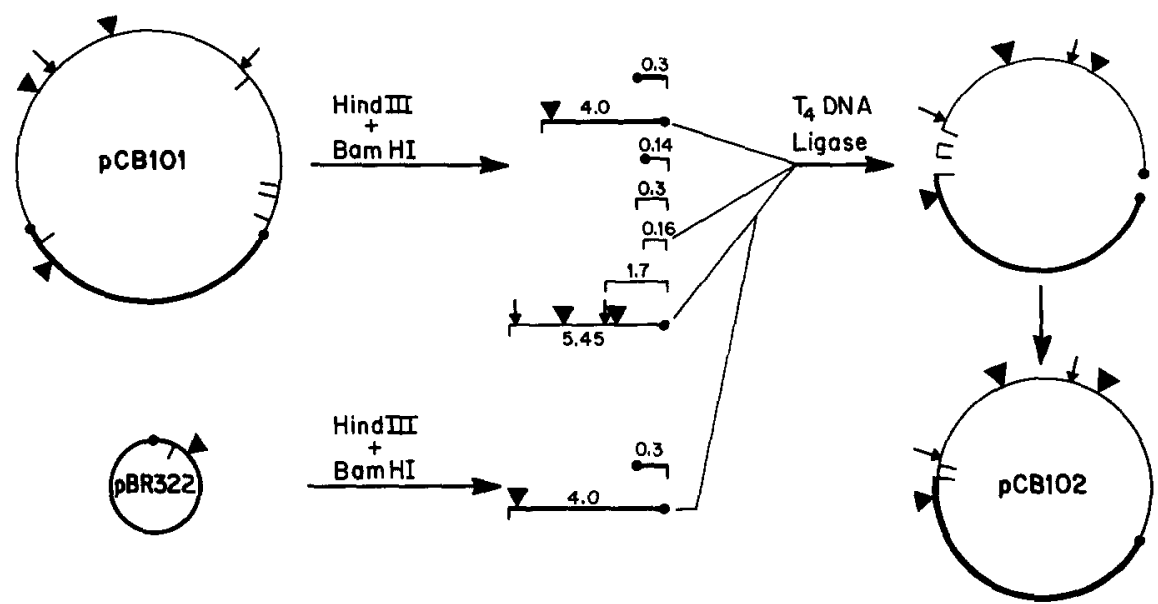

Fig. 3. Molecular events leading to construction of pCB102. Plasmids pCB101 and pBR322 were each digested with BamHI and HindIII, mixed, and incubated with $\mathrm{T}_{4}$ DNA ligase. The replicator region and ampicillin resistance genes are both contained on a $4.0 \mathrm{~kb} B a m \mathrm{HI}$ - HindIII fragment of pBR322 so this fragment must be included in the final recombinant. Strain EG47 transformed with pCB102 can grow with urocanate as sole carbon and nitrogen source. The $5.45 \mathrm{~kb} \mathrm{BamHI}-$ HindIII fragment of $K$. aerogenes is the only one large enough to carry the three genes needed for growth on urocanate, therefore this fragment must also be included. Single digests with either BamHI or HindIII indicate a single site for HindIII and two adjacent sites 160 base pairs apart for BamHI. A double digest with BamHI and HindIII gave the two fragments minimally required plus the fragment of 160 base pairs. Only one orientation is possible, as depicted as pCB102. Further single and double digests with BglII, SalI, and EcoRI confirmed the order shown here, where the orientation of the remaining $K$. aerogenes sequences with respect to the pBR322 sequences is inverse to that seen in pCB101 (see Fig. 1). The orientation of the $160 \mathrm{bp}$ BamHI fragment relative to other $K$. aerogenes sequences is unknown. For restriction site code, see Fig. 2

could not be determined. Therefore, this BamHI site could be either at position 7.44 as shown or at position 7.58 .

\section{Mapping the hutP Region}

Our analysis of the in vitro transcripts synthesized from the promoter region (hutP) of the hutUH operon (Nieuwkoop, Boylan, and Bender, manuscript in preparation) required a map of the hutP region including sites for some enzymes not used in the preceding section. The $h u t P$ region lies on the $3.1 \mathrm{~kb} B g I \mathrm{II}$ fragment, just to the right of the
Sall site at position 3.35 (Boylan and Bender, Abstr Annu Meet Am Soc Microbiol 1983, H154, p 131), so restriction sites in this region were determined first. Plasmid pCB106 was digested with $S a l l$ and the ends were radioactively labeled using DNA polymerase I. This end-labeled DNA was then further digested with either PvuII or PstI and the resulting fragments were separated by polyacrylamide gel electrophoresis under denaturing conditions. The polyacrylamide gel was autoradiographed and the results (Fig. 5) showed that the nearest PvuII and PstI sites were $240 \mathrm{bp}$ and $56 \mathrm{bp}$ from SalI, respectively, and that the order de- 


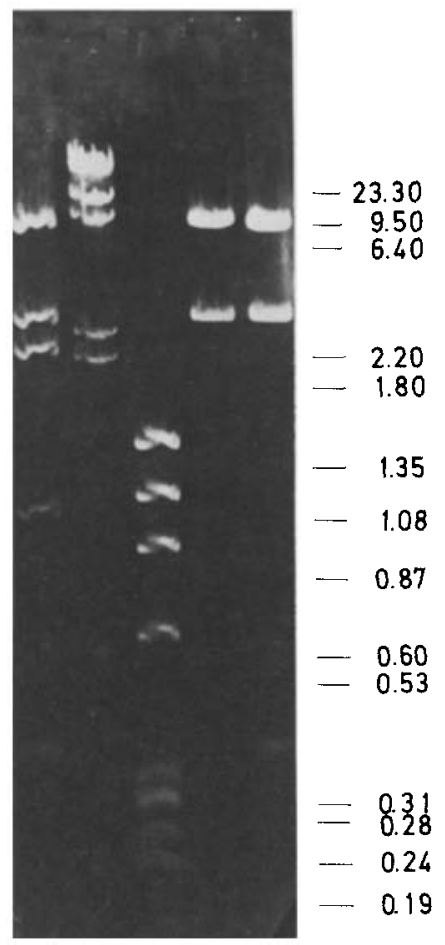

12345

Fig. 4. Restriction digest patterns on a $1 \%$ agarose gel of pCB103 and pCB101 DNA cut with $S a l I$ and/or $B g l I I$ endonucleases. Lane 1, pCB101 DNA cut with $S a l I$ and $B g I I I$ (five fragments, including one at $0.35 \mathrm{~kb}$, are visible on the original photograph); Lanes 2 and $3, \lambda$ DNA cut with HindIII and $\phi$ X174 DNA cut with HaeIII respectively, as size standards; Lane 4 , pCB103 DNA cut with Sall (fragment sizes 6.4 and $2.6 \mathrm{~kb}$ ); Lane 5, pCB103 DNA cut with $S a l I$ and $B g l I I$ (fragment sizes $6.1,2.6$, and $0.35 \mathrm{~kb}$ ). Although it is difficult to see that the $6.4 \mathrm{~kb} S a l$ fragment from pCB103 (lane 4 ) is reduced to $6.1 \mathrm{~kb}$ after digestion with $B g h I$, it is clear that the $2.6 \mathrm{~kb}$ SalI fragment, present in both pCB101 and pCB103, was not cleaved. Thus the single Sall site in the hut DNA of pCB103 is closer to the SalI site in pBR322 sequences than is the $B g I I$ site. The numbers at the right of the figure are the sizes (in $\mathrm{kb}$ ) of the standards.

duced from previous experiments (SalI-PstI-PvuII) was correct. (A similar experiment using pCB103 digested by $B g I I I$ showed that the PstI site at position 5.5 lies 50 bp to the right of the $B g I I I$ site).

There are more than eight HaeIII sites between the two $B g l I I$ sites in pCB101 (Fig. 5). To determine the location of the HaeIII sites flanking the hutP region, the $3.1 \mathrm{~kb} B g / \mathrm{II}$ fragment from pCB101 was purified and digested with $S m a \mathrm{I}$ and HaeIII. As expected, SaII (which cleaves the BgIII fragment once) cleaved only one $630 \mathrm{bp}$ fragment to a $560 \mathrm{bp}$ and a $78 \mathrm{bp}$. Given the known positions of the $S m a \mathrm{I}$ and SalI sites at positions 3.05 and 3.35 , the $560 \mathrm{bp}$ fragment must extend from Sall to a HaeIII site to the right. Thus there must also be a HaeIII site $78 \mathrm{bp}$ to the left of the SalI site at position 3.35. Similarly, HinfI cleaves the $3.1 \mathrm{~kb}$ BglII fragment (positions 2.35-5.45), purified from pCB101, into four fragments, the largest of which was $2.1 \mathrm{~kb}$. SalI, which cuts $1.0 \mathrm{~kb}$ from the left end of the $B g I I$ fragment, also cut $1.0 \mathrm{~kb}$ from the $2.1 \mathrm{~kb}$ HinfT fragment without affecting the other HinfI fragments (data not shown). Therefore, there must be a HinfI site at map posi-

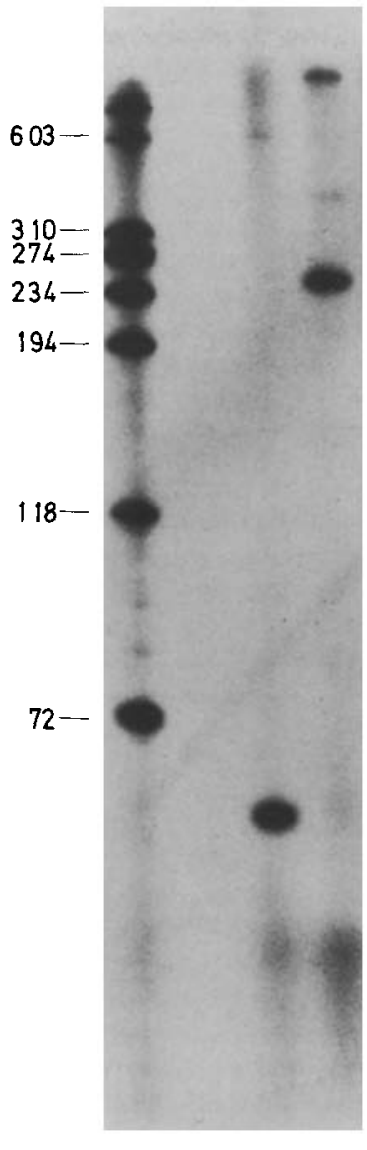

A

A 1

2

3
B 4

5

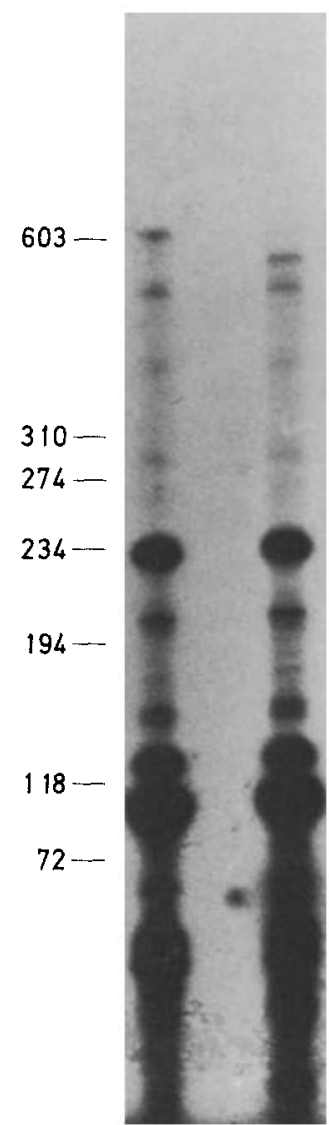

Fig. 5. A Autoradiogram of pCB106 DNA end-labelled at the SalI site and further digested with either PvuII (lane 3) or PstI (lane 2). These fragments and the HaeIII digest of $\phi X 174$ (size standard) in lane 1 were separated in a $7 \%$ polyacrylamide gel under denaturing conditions. B. Autoradiogram of purified $B g l I I$ fragment DNA digested either with HaeIII and SmaI (lane 4) or HaeIII, SmaI, and Sall (lane 5). These fragments and the HaeIII-cleaved $\phi X 174$ size standards (not shown) were end labelled after cleavage and separated in a $4 \%$ polyacrylamide under denaturing conditions

tion $4.45,2.1 \mathrm{~kb}$ from the left end of the $B g / I \mathrm{I}$ fragment, and two more HinfI sites somewhere between map position 4.5 and 5.4 the remaining part of the $B g I I I$ fragment.

Thus, the PstI, PvuII, and HaeIII sites in the immediate vicinity of $h u t P$ were located precisely and the position of the HinfI site nearest hutP was also determined. The location of the remaining HinfI and HaeIII sites in pCB101 have not yet been determined.

\section{Discussion}

We have cloned the hut operons from $K$. aerogenes into the HindIII site of the plasmid pBR322 in both orientations and have characterized a set of deletion derivatives lacking various portions of hut DNA. The cloned hut operons allow $E$. coli strains to use histidine and urocanate as sole carbon and nitrogen sources, independent of the orientation of the hut genes relative to $\mathrm{pBR} 322$, demonstrating that the hut genes are transcribed from their own promoters. Although hut gene expression responds to repression by the hutC product (the hut specific repressor) and by the nitrogen 
regulatory system, the regulation of hut expression from this high copy number plasmid is clearly different from the regulation of chromosomal hut. The degree of repression imposed by the hutC product is about three-fold, in contrast to the ten-fold repression seen with chromosomal $h u t$. It is difficult to predict the regulatory effects of increasing the copy-number of the hut operons. Both the hutC gene and the target sites for $h u t C$ gene product (repressor) would be present in multiple copies. Since hutC expression may also be regulated (Nieuwkoop et al., manuscript in preparation), prediction is even more difficult. In addition glucose regulates the urocanate transport system of $K$. aerogenes (Schlesinger and Magasanik 1965) and may similarly affect transport of the inducer in $E$. coli.

Activation of hut expression in response to carbon starvation requires CAP + cAMP (Prival and Magasanik 1971). The absence of such activation in strain EB896 remains unexplained. Carbon limitation stimulated the formation of $\beta$-galactosidase in this strain normally (not shown), therefore the CAP+cAMP system was fully functional. Moreover, hut expression from this plasmid showed a threefold stimulation under carbon-limited growth conditions in a $K$. aerogenes background (not shown). The regulation of several operons encoding catabolic genes is known to be sensitive to the degree of superhelicity in the region of the genes. Perhaps the fact that the operons are on a small plasmid alters the local superhelix density near the promoters and hence the susceptibility of hut to activation by CAP + cAMP or the nitrogen factor(s).

Our data agree in several general ways with the preliminary map of this region reported by Blumenberg and Magasanik (1981). We both identify a central BglII fragment, a very asymmetric distribution of BamHI sites, and the existence of two, three, and four cleavage sites for SalI, $S m a \mathrm{I}$, and $K p n \mathrm{I}$ respectively.

With the cloning of the hut operons, determination of restriction sites within the clone, and the generation of the deletion plasmids from pCB101, we have been able to align the genetic and physcial maps of the $K$. aerogenes hut genes (Boylan and Bender 1983) and to begin analyzing the regulation of $K$. aerogenes hut transcription in vitro (Nieuwkoop and Bender, Abstr Annu Meet Am Soc Microbiol 1983, \# H155 p 131).

Acknowledgements. We thank P. Weinstein for assistance in mapping pCB102, S.L. Allen for reading the manuscript and A.J. Nieuwkoop for helpful discussions. This work was supported by research grants from the National Institutes of Health, Public Health Service (AI-15822 and GM-27111) and by a Junior Faculty Research Award (JFRA-3) to RAB and postdoctoral fellowship (PF-1739) to SAB from the American Cancer Society.

\section{References}

Adams J, Kinney T, Thompson S, Rubin L, Helling RB (1979) Frequency-dependent selection for plasmid-containing cells of Escherichia coli. Genetics 91:627-637
Anderson EH (1946) Growth requirements of virus-resistant mutants of Escherichia coli stain B. Proc Nat Acad Sci USA $32: 120-128$

Bender RA, Janssen KA, Resnick AD, Blumenberg M, Foor F, Magasanik B (1977) Biochemical parameters of glutamine synthetase from Klebsiella aerogenes. J Bacteriol 129:1001-1009

Blumenberg M, Magasanik B (1979) A study in evolution; the histidine utilization genes of enteric bacteria. J Mol Biol $135: 23-37$

Blumenberg M, Magasanik B (1981) Physical maps of Klebsiella aerogenes and Salmonella typhimurium hut genes. J Bacteriol 145:664-667

Boylan SA, Bender RA (1984) Genetic and physical maps of Klebsiella aerogenes genes for histidine utilization $(h u t)$. Mol Gen Genet 193:99-103

El-Gewely MR, Helling RB, Farmerie W, Barnett WE (1982) Location of a phenylalanine t-RNA gene on the physical map of the Euglena gracilis chloroplast genome. Gene 17:337-339

El-Gewely MR, Helling RB (1980) Preparative separation of DNAethidium bromide complexes by zonal density gradient centrifugation. Anal Biochem 102:423-428

Gilbert W, Maxam A (1973) The nucleotide sequence of the lac operator. Proc Nat Acad Sci USA 70:3581-3584

Goldberg RB, Hanau R (1980) Regulation of Klebsiella pneumoniae hut operons by oxygen. J Bacteriol $141: 745-750$

Goldberg RB, Magasanik B (1975) Gene order of the histidine utilization (hut) operons in Klebsiella aerogenes. J Bacteriol 122:1025-1031

Goldberg RB, Bloom FR, Magasanik B (1976) Regulation of histidase synthesis in intergeneric hybrids of enteric bacteria. $\mathrm{J}$ Bacteriol 127:114-119

Holmes DS, Quigley M (1981) A rapid boiling method for the preparation of bacterial plasmids. Anal Biochem 114:193-197

Lederberg EM, Cohen SN (1974) Transformation of Salmonella typhimurium by plasmid deoxyribonucieic acid. J Bacteriol 119:1072-1074

Morrison DA (1977) Transformation in Escherichia coli: cryogenic preservation of competent cells. J Bacteriol 132:349-351

Neidhardt FC, Magasanik B (1957) Reversal of the glucose inhibition of histidase biosynthesis in Aerobacter aerogenes. J Bacteriol 75:253-259

Prival MJ, Magasanik B (1971) Resistance to catabolite repression of histidase and proline oxidase during nitrogen-limited growth of Klebsiella aerogenes. J Biol Chem 246:6288-296

Schlesinger S, Scotto P, Magasanik B (1965) Exogenous and endogenous induction of the histidine-degrading enzymes in Aerobacter aerogenes. J Biol Chem 240:4331-4337

Smith GR (1971) Specialized transduction of the Salmonella hut operons by coliphage $\lambda$ : Deletion analysis of the hut operons employing $\lambda$ phut. Virology 45:208-223

Struhl K, Cameron JR, Davis RW (1976) Functional genetic expression of eukaryotic DNA in Escherichia coli. Proc Nat Acad Sci USA 73:1471-1475

Sutcliffe JG (1978) Complete nucleotide sequence of Escherichia coli plasmid pBR322. Cold Spring Harbor Symp Quant Biol 43: $77-90$

Communicated by G. O’Donovan

Received June 25, 1983

\section{Note Added in Proof}

Recent work indicates that the BamHI site at position 5.6 in Fig. 1 is actually a pair of BamHI sites separated by about $50 \mathrm{bp}$ (Schwacha and Bender, unpublished observation), further emphasizing the asymmetric distribution of BamHI sites in this region. 